\title{
Strategic Timing of Commercial-Scale Tidal Energy Investment
}

\author{
Shelley L. MacDougall \\ Acadia Tidal Energy Institute, Acadia University \\ Wolfville, Nova Scotia, Canada \\ shelley.macdougall@acadiau.ca
}

\begin{abstract}
The many uncertainties in tidal energy conversion combine to form a significant barrier to raising private-sector capital. Mitigation and management of risk are essential if the industry is to attract equity investors. One way to manage the risk is through investment timing. The option to time an investment has value, which can be estimated. An analysis of an invest-vs-delay decision revealed a persistent, economicallyrational incentive to delay. Further inquiry identified a strategic rationale for delaying investment in tidal energy projects, given the uncertainty still present in the undertaking. As the largest sensitivity in the value of delay is the volatility of the investment's expected cash flows, an investigation into the prevalent uncertainties was undertaken.
\end{abstract}

This paper summarizes the real option valuation model. It then reports on results of a qualitative study of the predominant uncertainties facing developers and conditions that would help move the industry along. Predominant uncertainties reported revolve around technology reliability; site and resource knowledge; prospects for buildout; predictability of government policy and supports; prospects of off-take agreements; and supply chain capacity and costs. These are related back to the variables in the real option pricing model. The model is relevant for companies wishing to systematically evaluate timing options and communicate project value to the investment community. It can also be used by governments to evaluate the design of policies and financial supports in a way that is consistent with the priorities of financial markets.

Keywords -- Strategic investment timing; risk-reduction; real option valuation; government policy; instream tidal energy

\section{INTRODUCTION}

The journey toward commercial production of electricity from tidal streams has been neither straight nor smooth. The nascent industry has surged and receded like the tides themselves. Though there have been many setbacks over the years, there has been considerable progress. Supportive governments have helped with this progress but the timelines turned out to be much longer than originally anticipated. There have been many reassessments of expected global installed capacity, global economic potential, and cost of energy from the tides, and the pace of development.

After the initial burst of enthusiasm waned, private-sector investment became, for the most part, scarce. Investors have become cautious as more is understood about the challenges to be overcome. In a financing impasse of sorts, the ability to reduce the uncertainty by deploying devices and logging operating hours is thwarted by the absence of financing to undertake such projects [1]. Companies have been persevering, however, by staging their investments [2]. These investment timing decisions are a way to reduce the capital put at risk. This paper reports on a qualitative study of technology and project developers, the strategic rationale behind timing decisions, the predominant uncertainties giving them pause, and the valuation of the option to delay. Understanding these decisions and the model for valuing them can be useful for companies seeking investors and jurisdictions aiming to attract companies to develop their tidal resources.

\section{LITERATURE REVIEW}

Investment in commercial-scale instream tidal energy conversion is still quite risky. It requires a high, up-front commitment of capital, which is largely irreversible, and it has a long investment horizon. Leete et al. [3] collected the perspectives of early investors in marine renewable energy companies regarding investment preferences, incentives and barriers. Their concerns include a lack of performance data of commercial-scale devices and arrays in terms of energy yield, costs, and reliability and the absence of manufacturers' warranties. Also, investors describe experiences with overoptimism on the part of technology developers regarding timelines, costs and performance estimates. The lack of stability and predictability of government policy and support constitutes another disincentive to invest.

Governments have introduced technology-push policies such as R\&D grants, demonstration grants and exclusive licenses, and market-pull policies such as renewable portfolio standards, renewable obligation certificates (ROCs), and feedin tariffs (FITs), in various combinations. These are among the policies investors favour most [4]. Barriers, as well as government policies and supports, vary by jurisdiction and change over time.

Even with the supportive renewable energy policies and funding in Scotland, France and Nova Scotia for tidal energy conversion, private-sector investment has been scant. The investment does not fit the investment criteria of most angel, private equity, or project financing arrangements. Industrials have entered in some cases, bringing corporate venture capital, but the next investment, installing a commercial-scale device or pre-commercial array, is too large and risky for balance sheet financing by even large, publically-traded companies.

Leete et al. [3] and Masini and Menichetti [5] call for research to be done to better understand investor priorities so governments can develop policies and financial supports that will facilitate the raising of private-sector financing: "It is essential that private capital is accessed in order to accelerate 
development and deployment of the technology" [3, p. 867]. Government policy-makers would benefit from a better understanding of how various policies attract or deter investors and what policies will draw equity investment. This paper seeks to provide insight into the invest-versus-delay decision, the value of delay, the prevalent uncertainties now faced, and strategic rationale behind the timing decision.

\section{A. Real options value and the value of delay}

Bucher et al. [1] noted one way to attract investors is to demonstrate device performance but the financing needed to do it cannot be raised. They sought methods to de-risk the technology in order to gain investor confidence and market acceptance. Investment timing - building in stages or delaying an investment - can help overcome this financing conundrum and manage the financial risk. An option to delay investment or build in stages has asymmetrical risk and its value can be measured, at least estimated, in a manner consistent with equity valuation in finance, using real option valuation.

The value of a firm, and by extension, the value of its equity, is a function of its expected free cash flows [6]. Company owner-managers and managers acting as agents for shareholders recognize the need to invest capital to generate net positive free cash flows into the future. Financial markets ascribe value to the free cash flows coming directly from the investments a company undertakes. It also values the options those investments create.

The Nobel Prize-winning option pricing model by Black and Scholes [7], adapted for use with optional investments in real assets [7]-[11], values the real options in a manner consistent with the equity valuation principles in finance. Though it is difficult to capture the exact value of a real option due to the non-tradability of the real asset and the existence of compound options, the model can guide capital investment decisions that align with how the market values the firm and its equity.

The Black-Scholes option pricing model [7] for a dividend-paying European stock option is as follows:

$$
\begin{aligned}
& V=S e^{-\delta t} N\left(d_{1}\right)-X e^{-\mathrm{rft}} N\left(d_{2}\right) \\
& d_{l}=\left[\ln (S / X)+\left(r_{f}-\delta+\sigma^{2} / 2\right) t\right] / \sigma \sqrt{ } t
\end{aligned}
$$

and

$$
d_{2}=d_{1}-\sigma \sqrt{ } t
$$

where:

$V=$ the current value of the call option

$S=$ the current price of the underlying share

$X=$ the exercise or strike price (present value)

$r_{f}=$ the risk-free rate of interest, continuously

compounded

$e=2.7183$

\footnotetext{
${ }^{1}$ Being able to exercise at any time before expiry is a valuable feature of an American option but its valuation is more complicated. Using the pricing
}
$N(d)=$ cumulative normal probability density
function.
$\delta=$ the payout rate or dividend rate on the project.
$t=$ the time left until expiry
$\sigma=$ standard deviation of the stock's rate of return
$\ln (S / X)=$ the natural logarithm of the ratio of share price to exercise price.

Applying the option pricing model for a financial asset to a real asset, the terms are applied as shown in Table 1 [9].

TABLE I

INPUT VARIABLES AND RELATIONSHIP TO OPTION VALUE

\begin{tabular}{lll} 
Variable & \multicolumn{1}{c}{ Definition } & $\begin{array}{c}\text { Relationship } \\
\text { to call option } \\
\text { value (V) }\end{array}$ \\
\hline $\mathrm{S}$ & $\begin{array}{l}\text { Present value of expected benefits, } \\
\text { discounted at cost of capital }\end{array}$ & Direct \\
$\mathrm{X}$ & $\begin{array}{l}\text { Present value of expected costs, } \\
\text { discounted at the risk-free rate }\end{array}$ & Indirect \\
$\sigma$ & $\begin{array}{l}\text { Volatility of expected cash flows, } \\
\text { measured by standard deviation } \\
\text { Leakage rate (foregone benefit each } \\
\text { year by waiting in \%) }\end{array}$ & Indirect \\
$\mathrm{t}$ & Time to expiry (years). & Direct \\
\hline
\end{tabular}

The variables $\mathrm{S}$ and $\mathrm{X}$ are similar to the values used in net present value and internal rate of return calculations, typically used to evaluate capital investments. $S$, or the present value of expected benefits, is the same in both models. X, or present value of expected costs, differs only by the discount rate used. As well, the period of discounting is different - the European option pricing model assumes the cash will begin to flow upon exercise at the end of the option period, if at all.

While the cost of investing (exercising the option) is greater than the value of the inflows $(\mathrm{S}<\mathrm{X})$, the option is "out of the money" and in makes economic sense to wait. Once $S>X$, the option is "in the money" and can be exercised. Theoretically, it is sub-optimal to exercise an option until just before expiry because the option value can still increase over the remaining time. However, in practice, managers may find compelling qualitative or hard-to-quantify reasons to exercise before expiry. ${ }^{1}$

The option to delay an investment has value because, while waiting, conditions change. As well, with the passage of time, some uncertainty is resolved. Costs may be less and/or more certain, technology reliability and revenues may be greater and/or more certain. With better cost and revenue estimates, the cost of capital may also be less. Naturally, the time to expiry shortens, assuming there is a time limit on how long the developer can wait before losing the opportunity to invest. These all affect the value of the optional project.

The value of an option to invest differs from the net present value of the investment because of asymmetrical risk. The holder of the option, such as a seabed lease for future

model for a European option is practical and generates a conservative estimate of the American option value. 
development, has the right but not the obligation to make the capital investment. Much less is lost if, while holding the option, conditions change that no longer favour the investment. The upside potential but limited downside risk makes the option particularly valuable.

In an effort to ascertain whether some of the delays observed in the industry were strategic in nature, MacDougall [2] analyzed an investment in a $10 \mathrm{MW}$ instream tidal energy array and the value of the option to delay. Following a scenario and sensitivity analysis using the Black-Scholes model [7], MacDougall noted a somewhat persistent and economicallyrational incentive to delay investment. Holding an option to invest has value. Delays witnessed in the industry may be, in part, due to strategic investment timing.

A qualitative study was then undertaken [12] to delve into the strategic rationale behind an invest-vs-delay decision in tidal energy development. From a series of interviews with decision-makers in the tidal energy industry, it was observed that technology and site developers are acquiring seabed leases in multiple locations and jurisdictions, holding them as options for later development. ${ }^{2}$ It was also found that companies with multiple sites are staging their investments across their various sites, according to their own readiness (technological and organizational) and the particular conditions at the various sites. Staging allows companies to make smaller investments and learn and improve their technology and procedures before committing more capital. It also allows them to invest where the jurisdiction's policies, infrastructure, and tidal resources are the most suitable for next steps. As in the research by Bjorgrem et al. [13] and Lovedal and Neumann [14], it was observed that companies are willing to internationalize at the pre-commercial stage, such as by partnering with local companies, to go where the next best opportunity to successfully deploy exists. These strategic timing decisions - the staging of investments - are examples of real option acquisition, management and exercise [15]. While the companies may not be using the real option valuation model explicitly, the use of real option reasoning is evident.

\section{B. Uncertainty and the value of delay}

With these findings in hand, this paper returns to the invest-versus-delay analysis done in [2] to further explore key drivers in the timing decision.

Of the input variables $\sigma, \delta$, and $\mathrm{t}$ in the real option model, the value of the option is most sensitive to volatility $(\sigma)-$ the unpredictability of the cash flows. Even while the option is out of the money $(S<X)$, it still has a speculative value. As volatility is reduced and the option expiry date nears, this speculative value decreases. If and when the option becomes in the money $(\mathrm{S}>\mathrm{X})$, the option can be exercised, though holding it longer may still be preferable. If the option expires while still out of the money, all that was lost was the cost of obtaining and holding the option.

\footnotetext{
${ }^{2}$ Of the ten participating organizations, four were primarily technology developers, four were project developers, and two were demonstration/test centers. Two of the project developers were developing only one tidal energy site (though involved in other types of energy projects), while the other six
}

Being that uncertainty of cash flows is an important driver in the value of the option to delay, the sources of uncertainty in tidal energy development and their mitigation deserve further inquiry. As part of the interviews in the above-noted study [12], respondents were asked what they felt were the predominant uncertainties in commercializing tidal energy conversion at the time and in the various locations where their organization had been involved; and what conditions they felt would tip the balance toward a decision to invest and move the industry along. Results from the analysis of responses to these questions are reported next. Noted conditions that can affect the real option value will then be related back to the variables in the valuation model.

\section{METHOD}

The study consisted of interviews of senior managers and executives of ten organizations in the tidal energy industry. The respondents were purposefully selected. Thirteen organizations were asked to participate and ten agreed. Four of the organizations were technology developers, four were site developers, and two were test/demonstration centres. Of the eight companies (technology and site developers), all but two had been involved in projects in more than one jurisdiction. The jurisdictions were the UK, France and Nova Scotia, Canada. The semi-structured, face-to-face interviews were $60-80$ minutes in duration and were conducted in 2015.

The interviews were recorded and transcribed. Using the constant comparative method of data analysis, major and minor themes were drawn from the responses.

\section{RESULTS}

When asked about the predominant uncertainties in commercializing tidal energy conversion and the conditions they felt would tip the balance toward a decision to invest and move the industry along, respondents were quite like-minded. The dominant themes that emerged from their responses are described below.

\section{A. Technology reliability}

The uncertainty surrounding the ability of the technology to hold up in the harsh marine environment arose as the most dominant theme: how well and how long the technology would perform and what the frequency and nature of unscheduled maintenance would be.

Technology reliability. Everything hinges on that. ... In the model of five-year operations, maintenance, planned maintenance of the turbine ... we have, obviously, assumptions in there. The world isn't always great and things will break down ... so our model does have a number of interventions to fix it, and downtime and so on. We've been fairly conservative but if they start going

companies were involved in multiple sites. Of the companies (technology and site developers), three had had undertakings in only one country, two in two countries, and three in three countries. 
worse than our assumptions, then our investors will know that. (Organization 3)

\section{B. Site and resource knowledge and room to build out}

Areas where there is a lack of knowledge of the site characteristics and the resource present a large amount of uncertainty. With thorough site assessment and resource measurement, developers can better "right-size" the turbines, plan their appropriate placement, and estimate the energy yield. Knowledge of the site and the resource also help developers determine if their installation procedures and technology designs are suitable and ready for deployment in those particular conditions.

\section{Resource analysis is key. (Organization 8)}

As well, having an energetic site is important for the economics of the project:

The more yield you get, the better it is. Believe me, in the model, the biggest sensitivity in any tidal model has nothing to do with capital costs; it's all about yield. So it really says, the first site you should have gone to is the high-yield site. Bay of Fundy, it's a good site. Yield. But with yield, comes risk. Installation risk. (Organization 8)

Related to the site knowledge is the availability of space to build out beyond demonstration devices and arrays and prospects for permits to build commercial arrays. As noted by one respondent,

[Sites limited to] ten megawatts are a waste of time. Why would you do it? You need to get your product of the ground [but] we've gone past that. People are not realizing that ... we're not doing [this] for the sake of the widget, we're doing [it] for the sake of the investor. So, my view is, obviously, we'd like to see more turbines going in. Do we need 10 MW sites for that? Probably not. (Organization 3)

Sites where there is potential for building out, in terms of the resource, physical space, infrastructure, government policy, a path forward for permitting and consenting, and foreseeable supply chain capacity, offer the potential for reaching sufficient economies of scale and the potential to bring down the cost of energy.

The economics will work if they build out. The French site has been selected so they can build out. The advantage of the French sites is they've got nice flow but they've got a big, fat grid connection just on the shore. It is ready to go. (Organization 8)

\section{Suitability and predictability of government policy} and financial support

A major area of uncertainty is related to government policy, funding and financial supports. Companies seek sufficient and predictable support that is flexible and patient. Developers need visibility; they need to know what the price support will be beyond 2019 in the UK and beyond $25 \mathrm{MW}$ in Nova Scotia. A major impediment to progress is the lack of infrastructure, particularly grid access, in some jurisdictions. Government investment in infrastructure reduces the upfront costs and uncertainty for developers.

We can put certain money at risk but if there is no clarity, then we have to stop. (Organization 4)

France's blend of capital support, feed-in tariff, and infrastructure investment is viewed as a step toward building the industry.

\section{Prospects of off-taker agreements}

Where developers have strategic alliances with utilities, the prospects for sale of electricity are far more certain than for independent power producers. Even with a feed-in tariff in place, the lack of off-take agreements is making raising of capital especially difficult.

The government is moving through this policy about how we're going to permit and things like that - those things are coming along - but the real driver of this is the power purchase agreement. We haven't been able finance our project because we don't have an executed power purchase agreement. If you have a PPA, people will pay attention, if you don't, they've got other things to do. (Organization 1)

\section{E. Supply chain capacity and cost}

Another major source of uncertainty facing developers is supply chain capacity and the cost of materials, such as steel, and services. In the relatively unindustrialized and rural coastal communities located near the tidal resources, the supply chain is thin.

I think the biggest challenge for us is the price, cost structure, in terms of services, installation work, for example, and from the supply chain, regarding steel works, for example. I mean, our device mainly, really, is a steel structure. ... It's really hard to find competitive steelwork prices here. On the marine operations side, it is a lack of equipment sometimes. (Organization 5)

Government support to build supply chain capacity and support innovation is needed to reduce uncertainties around construction, installation, maintenance and operation of equipment.

\section{DISCUSSION}

As described by the respondents in this study, the predominant uncertainties in tidal energy development revolve around technology reliability; site and resource knowledge; prospects for buildout; predictability of government policy and supports; prospects of off-take agreements; and supply chain 
TABLE II

NOTED CONDITIONS AFFECTING REAL OPTION VALUE

\begin{tabular}{|c|c|}
\hline Variable & Noted conditions and changes thereto that affect variable value \\
\hline $\mathrm{S}$ & $\begin{array}{l}\text { Feed-in tariff (amount, duration) } \\
\text { Equipment reliability, utilization } \\
\text { Water speed } \\
\text { Energy yield, capacity factor } \\
\text { Economic life } \\
\text { Grid access }\end{array}$ \\
\hline$X$ & $\begin{array}{l}\text { Maintenance costs } \\
\text { Knowledge of resource affecting accuracy of design specifications } \\
\text { Supply chain capacity } \\
\text { Cost of materials and services } \\
\text { Infrastructure in place } \\
\text { Water speed, tidal range, distance from shore } \\
\text { Capital grant (reduces cost to owner) }\end{array}$ \\
\hline$\sigma$ & $\begin{array}{l}\text { Visibility of government policies, power purchases, future FITs } \\
\text { Knowledge of resource, site } \\
\text { Technology reliability, logged operating hours, data collected (knowledge of energy yield, breakdowns, repairs) } \\
\text { Construction cost uncertainty, delays } \\
\text { Interaction with marine environment } \\
\text { Likelihood of grid access }\end{array}$ \\
\hline$\delta$ & $\begin{array}{l}\text { Pace of development } \\
\text { Ability to secure rights to develop commercial site } \\
\text { Exclusivity of right to develop resource } \\
\text { Lease fees } \\
\text { Time limit on FIT }\end{array}$ \\
\hline $\mathrm{t}$ & Time limits to develop at site, duration of FIT, capital grants, pre-emptive entry by competitor \\
\hline
\end{tabular}

capacity and costs. Through investment staging, learning, and the willingness to develop in sites where the conditions are most favourable, developers are gradually overcoming the financing impasse.

The companies participating in the study model their projects extensively. It appears the options are being considered in decision-making, at least intuitively, in a manner consistent with the valuation discipline imposed by financial markets. Though these companies appear to be using real option reasoning [15], applying the real option valuation model would be a more systematic approach to evaluating the investment options by project and technology developers. Being consistent with the financial market's valuation of a firm and its equity, the model also offers a means of demonstrating project value to existing and potential investors. The conditions mentioned in the interviews, reported above and in [12], that affect the real option value and change over time are shown in Table II.

\section{CONCLUSION AND POLICY IMPLICATIONS}

This paper reported on a study of the strategic timing of investment in commercial-scale tidal energy devices and small arrays and the value of delay. Organizations in the international tidal energy industry were found to stage their investments across multiple tidal energy sites, even multiple jurisdictions, to mitigate risk. They demonstrated real option reasoning in their decision-making. This paper related the major

\footnotetext{
${ }^{3}$ Interestingly, Lovdal and Neumann [14] surveyed companies in the marine renewable energy industry in 2007 . They report the two most important barriers to commercialization perceived by the respondents were the need for
}

uncertainties faced by companies in commercializing tidal energy to the real options valuation model. The real options model offers companies a systematic approach for valuing timing options that is consistent with how the financial markets value the firm. It can also be used by developers to demonstrate the value of their projects to investors.

Wustenhagen and Menichetti [16] and others call for including an investor perspective in assessing the effectiveness of energy policies. For policy setting, there needs to be an understanding of the rationale behind the decisions being made by technology developer and project developer management on behalf of investors. The real option valuation model can be used by governments to assess policies and financial supports in a manner that aligns with investors' priorities.

Still more de-risking needs to be done to attract equity investment: technology, supply chain, resource measurement/site characterization, market access, and policy risks all need further mitigation and management. Government policy and supports continue to be important, while the uncertainty and costs of tidal energy are still high. ${ }^{3}$ The real option valuation model is an appropriate tool to help set government policy. It can be used by policy makers to design the offering - its package of infrastructure, site knowledge, supply chain, funding and financial supports - that it bundles with its naturally unique tidal resources. The model can be used to estimate the impact of changes to the package's elements on

capital and the need for supportive political schemes (p.1096). Eight years later, in 2015, the same sentiments are prevalent in participants' answers. 
the values of investing and delaying, in a manner consistent with the valuation of equity in financial markets.

\section{ACKNOWLEDGEMENT}

The authour would like to gratefully acknowledge the Harrison McCain Foundation for its financial support of the data collection phase of this study.

\section{REFERENCES}

[1] Bucher, R., Jeffrey, H., Bryden, I., Harrison, G., Creation of investor confidence: The top-level drivers for reaching maturity in marine energy, Renewable Energy, 88, 120-129, 2016.

[2] MacDougall, S.L., The value of delay in tidal energy development. Energy Policy. 87, 438-446, 2015.

[3] Leete, S., Xu, J., Wheeler, D., Investment barriers and incentives for marine renewable energy in the UK: An analysis of investor preferences. Energy Policy. 60, 866-875, 2013.

[4] Burer, M., Wustenhagen, R., Which renewable energy policy is a venture capitalist's best friend? empirical evidence from a survey of international clean tech investors, Energy Policy, 37, 4997-5006, 2009.

[5] Masini, A., Menichetti, E., The impact of behavioral factors in the renewable energy investment decision making process: conceptual framework and empirical findings. Energy Policy. 40, 28-38, 2012.

[6] Brigham E., and Daves, P., Intermediate Financial Management Southwestern, Ohio, 2013.

[7] Black, F., Scholes, M., The pricing of options and corporate liabilities. $J$. Political Economy. 81, May-June, 637-59, 1973.

[8] Dixit, A. K., Pindyck, R.S., Investment under Uncertainty. Princeton University Press, New Jersey, 1994.

[9] Myers, S., Determinants of corporate borrowing. J. Financial Economics, $5,147-75,1977$

[10] Myers, S., Finance theory and financial strategy. Midland Corporate Finance J. 5, (1), 6-13, 1987

[11] Trigeorgis, L., Real options: Managerial flexibility and strategy in resource allocation. MIT Press, Cambridge, 1996.

[12] MacDougall, S., Confronting the financing impasse: Risk management through internationally staged investments in tidal energy development. Int. J. Marine Energy, 18, 78-87, 2017.

[13] Bjorgum, O., Moen, O., Masden, T., New ventures in an emerging industry: access to and use of international resources, Int. J. Entrepreneurship and Small Business, 20 (2), 233-253,2013.

[14] Lovdal, N., Neumann, F., Internationalization as a strategy to overcome industry barriers - An assessment of the marine energy industry. Energy Policy. 39, 1093-1100, 2011.

[15] Trigeorgis, L., Reuer, J., Real options theory in strategic management, Strategic Management J., 38 (1), 42-63, 2017.

[16] Wustenhagen, R., Menichetti, E., Strategic choices for renewable energy investment: Conceptual framework and opportunities for further research. Energy Policy. 40, 1-10, 2012. 